Check for updates

${ }^{1}$ Department of Health Care

Policy, Harvard Medical School,

180 Longwood Ave, Boston, MA 02115, USA

${ }^{2}$ Division of Cardiology, Massachusetts General

Hospital, Boston, MA, USA

${ }^{3}$ Doximity, San Francisco, CA, USA

${ }^{4}$ Department of Medicine,

Massachusetts General

Hospital, Boston, MA, USA

${ }^{5}$ National Bureau of Economic

Research, Cambridge, MA, USA

Correspondence to: A B Jena

jena@hcp.med.harvard.edu

(or @anupambjena on Twitter)

Cite this as: BMJ 2018;363:k4859 http://dx.doi.org/10.1136/bmj.k4859

Accepted: 30 October 2018

\title{
Golf habits among physicians and surgeons: observational cohort study
}

\author{
Gal Koplewitz, ${ }^{1}$ Daniel M Blumenthal, ${ }^{2}$ Nate Gross, ${ }^{3}$ Tanner Hicks, ${ }^{1}$ Anupam B Jena ${ }^{1,4,5}$
}

\section{ABSTRACT}

OBJECTIVES

To examine patterns of golfing among physicians: the proportion who regularly play golf, differences in golf practices across specialties, the specialties with the best golfers, and differences in golf practices between male and female physicians.

DESIGN

Observational study.

SETTING

Comprehensive database of US physicians linked to the US Golfing Association amateur golfer database. PARTICIPANTS

41692 US physicians who actively logged their golf rounds in the US Golfing Association database as of 1 August 2018.

\section{MAIN OUTCOME MEASURES \\ Proportion of physicians who play golf, golf performance (measured using golf handicap index), and golf frequency (number of games played in previous six months).}

\section{RESULTS}

Among 1029088 physicians, 41692 (4.1\%) actively logged golf scores in the US Golfing Association amateur golfer database. Men accounted for $89.5 \%$ of physician golfers, and among male physicians overall, 5.5\% (37 309/683 297) played golf compared with $1.3 \%(4383 / 345489)$ among female physicians. Rates of golfing varied substantially across physician specialties. The highest proportions of physician golfers were in orthopedic surgery $(8.8 \%)$, urology $(8.1 \%)$, plastic surgery $(7.5 \%)$, and otolaryngology (7.1\%), whereas the lowest proportions were in internal medicine and infectious disease ( $13.0 \%)$. Physicians in thoracic surgery, vascular surgery, and orthopedic surgery were the best golfers, with about $15 \%$ better golf performance than specialists in endocrinology, dermatology, and oncology.

\section{CONCLUSIONS}

Golfing is common among US male physicians, particularly those in the surgical subspecialties. The association between golfing and patient outcomes, costs of care, and physician wellbeing remain unknown.

\section{Introduction}

Across the world, physicians report high rates of burnout. $^{1}$ Although leisure activities can improve wellbeing, those engaged in by physicians have not been well characterized. It has long been a stereotype of the medical profession that physicians spend much of their leisure time on the golf course $^{2}-$ in the United States, one long held belief is that physicians spend Wednesday afternoons on the golf course, and golfing among physicians seems to be common in other countries as well. ${ }^{34}$ The validity of these beliefs, however, has never been determined empirically. In particular, the proportion of physicians who regularly play golf, differences in golfing practices across specialties, the specialties with the best golfers, and differences between the golf habits of male and female physicians. The limited existing scientific literature on golf and medicine has focused on the sport's health benefits, including a recent international consensus statement, ${ }^{5}$ as well as on the propriety of physicians accepting golf related gifts from pharmaceutical companies. $^{6-8}$

Using a large database of amateur golfers linked to data on nearly all US physicians, we analyzed patterns of golfing among physicians.

\section{Methods}

Our study made use of two primary datasets, the Doximity physician database and the Golf Handicap and Information Network, a large database maintained by the United States Golf Association. ${ }^{9}$ The Golf Handicap and Information Network database is widely used by amateur golfers to log their scores, as well as to verify the handicap index of playing partners. The golf handicap index is a numerical measure of performance that allows golfers of different skill levels (ie, handicaps) to play against each other on equal terms. The handicap index for a given player is determined on the basis of that player's performance in various rounds of golf and, if applicable, on various golf courses (an adjustment is made for course difficulty to avoid players being penalized who achieve lower scores because they play more difficult golf courses). Lower numbers reflect better performance. The 
handicap difference between two competing players determines the additional number of golf strokes the player with the higher handicap (ie, the worse player) should be allowed to have an equivalent performance to a player with a lower handicap. By United States Golf Association rules, a player's handicap is issued by an authorized golf club or authorized golf association (through its member clubs). ${ }^{10}$

Doximity is a comprehensive database of nearly all US physicians-both those who are registered members of the online networking service as well as those who are not-assembled through multiple sources and data partnerships, including the National Plan and Provider Enumeration System, state medical boards, specialty societies such as the American Board of Medical Specialties, and collaborating hospitals and medical schools. The data, which are publicly available and include information on physician age, sex, specialty,

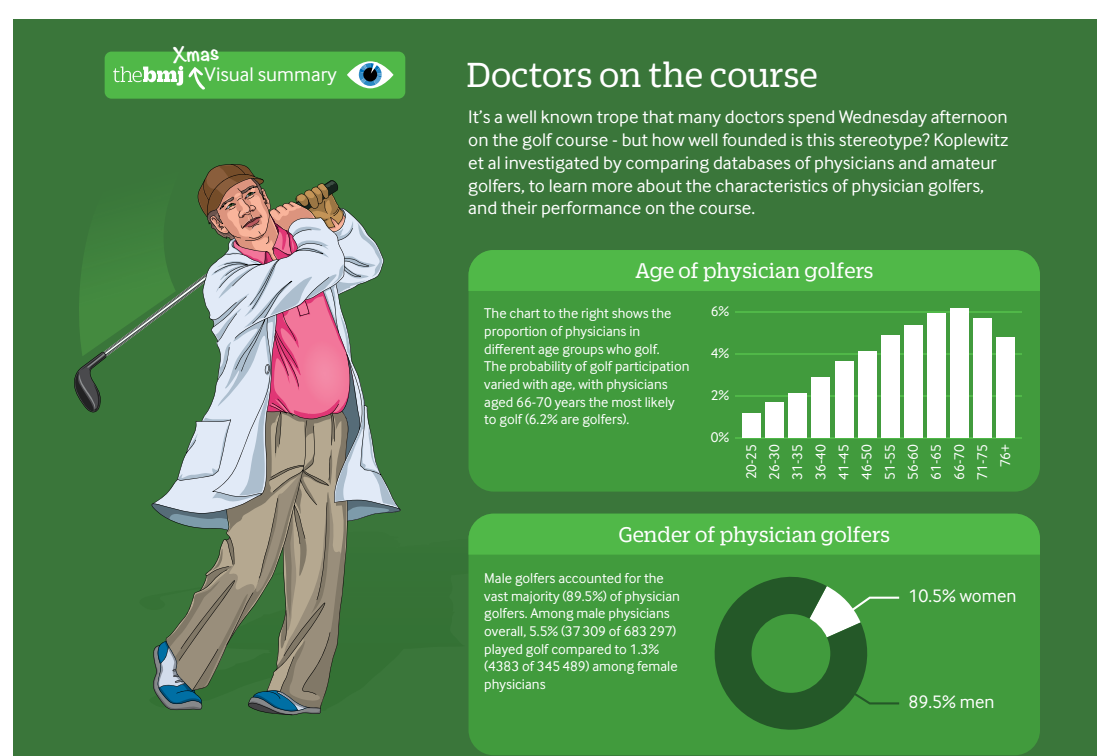

Physician golfers by specialty

Of course the burning question is about which specialty performs best on the course.
Below we present the top 10 specialties, as determined by three important metrics.
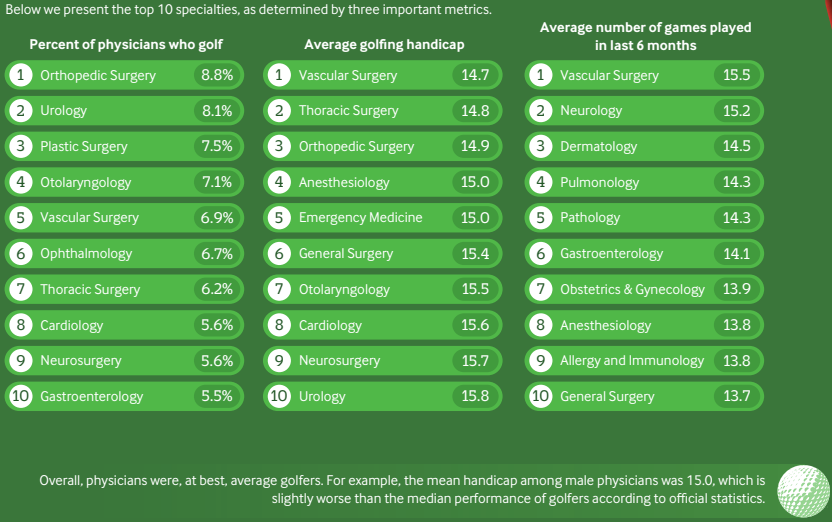

The association of golfing with patient outcomes, costs of care, and physician well-being are unknown.

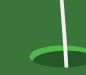

thebmi $\begin{gathered}\text { Read the full } \\ \text { article online }\end{gathered}$ http://bit.ly/BMJcfNICE

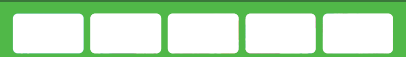

and other characteristics, have been validated and used in previous studies. ${ }^{11-14}$

For each physician in the Doximity database, we used full name and state of residence to automatically link with the Golf Handicap and Information Network database, extracting information on the number of games a physician logged in the previous six months and the physician's golf handicap.

We analyzed the proportion of physicians who regularly play golf, both overall and according to physician sex, age, and specialty. We also analyzed the frequency of golf rounds in the previous six months. Finally, to determine which specialties had the best golfers we analyzed how players' handicaps varied across physician specialty.

\section{Results}

Overall, our database included 1029088 physicians, of whom 4.1\% (41692) actively logged their golf scores. Male golfers accounted for $89.5 \%$ of physician golfers, and among male physicians overall, 5.5\% (37309/683 297) played golf compared with 1.3\% (4383/345 489) among female physicians. The probability of participation in golf varied with age, with male physicians aged 61-70 years most likely to play golf (6.9\% golfers) and female physicians aged 31-35 years least likely ( $0.8 \%$ golfers) (fig 1$)$. Among male physicians who played golf, the mean age was 55.2 years (median 56 years, interquartile range 46-64 years).

Rates of golfing and golf handicaps varied substantially across physician specialties (table 1). Specialties with the highest proportion of physicians who played golf included orthopedic surgery $(8.8 \%)$, urology $(8.1 \%)$, plastic surgery $(7.5 \%)$, and otolaryngology $(7.1 \%)$, whereas in specialties such as internal medicine and infectious disease, fewer than $3.0 \%$ of physicians played golf.

The average golf handicap was 16.0 overall, 15.0 for male physicians, and 25.2 for female physicians (fig 2). Physicians in vascular surgery, thoracic surgery, and orthopedic surgery, were the best golfers (table 1). The average handicap indices in these three specialties were $14.7,14.8$, and 14.9, respectively, whereas in specialties such as endocrinology, dermatology, and oncology the average handicap indices were greater than 17.0. The per cent of physicians who played golf in a given specialty was negatively correlated with golf handicap-better performance was observed in specialties with more golfers (correlation coefficient $-0.5, \mathrm{P}=0.002$, fig 3).

Male golfers played an average of 14.8 games in the first six months of 2018, and female golfers played an average of 12.1 games (table 1). At the physician level, playing more games was negatively correlated with golf handicap-that is, better performance was observed in golfers who played more frequently (correlation coefficient $-0.2, \mathrm{P}=0.004)$. 


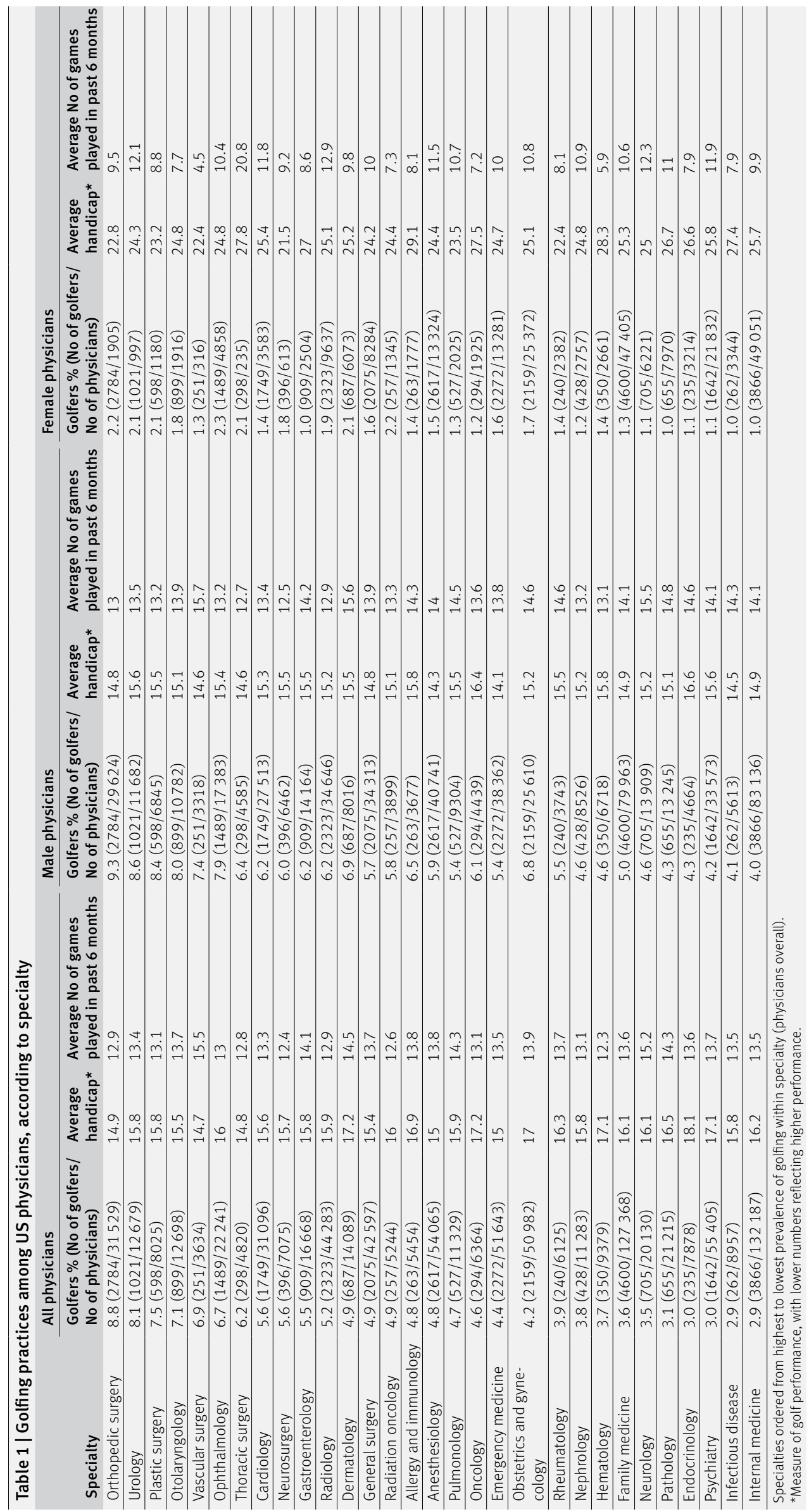




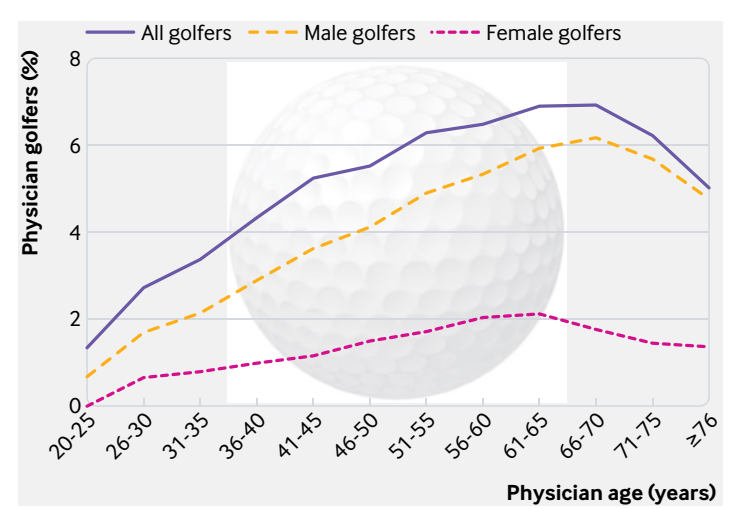

Fig 1 | Per cent of physicians who golf, according to physician age

\section{Discussion}

In an analysis of the golfing patterns of more than 40000 US physicians linked to a comprehensive physician database, we found that at least $4 \%$ play golf, with male physicians and surgical specialists spending the most time on the golf course. Surgical specialists reported the best golf performance, as measured by players' handicap, and better performance was observed in specialties with more golfers and among golfers who reported playing more games in the previous six months. Average handicaps for physicians in thoracic surgery, vascular surgery, and anesthesiology were about 15\% lower than those of physicians in endocrinology, dermatology, and oncology. This reflects substantially better golf skills on the part of the former three specialties (eg, according to the United States Golf Association, this scale of improvement is on par with the average $100 \mathrm{~m}$ dash time for college runners falling by a full second, or the average batting average in baseball increasing about 30 points). ${ }^{15}$ We also found that physicians in their late 60s and early 70s were most likely to play golf. It is unclear whether this is a generational preference or simply a matter of having more leisure time later in one's career.

Overall, physicians were, at best, average golfers. For example, the mean handicap among male physicians was 15.0 , which is slightly worse than the median performance of non-medical golfers according

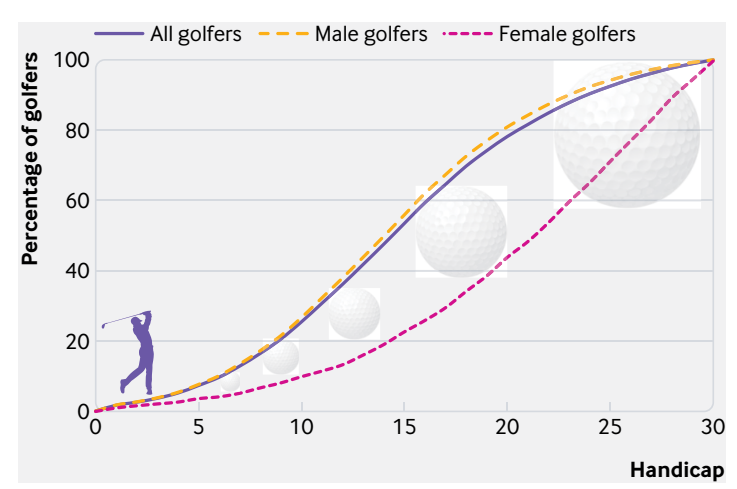

Fig 2 | Distribution of golf handicaps, by physician sex

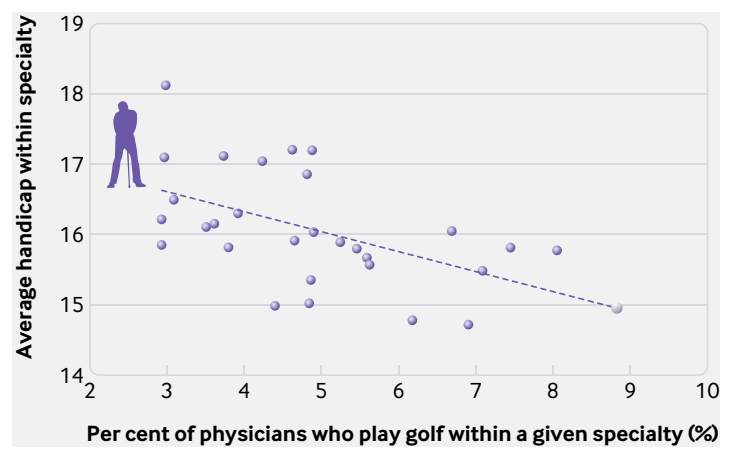

Fig 3 | Relation between golf handicap and percentage of physicians who play golf, by specialty (represented by dots)

to official statistics from the US Golf Association. ${ }^{16}$ Professional golfers, in comparison, routinely have handicaps of zero or lower.

The findings of this study suggest several areas where research is needed and where federal research support-perhaps through a dedicated agency of the National Institutes of Health-might be warranted. Is patient mortality associated with the amount of time a patient's physician plays golf (either negatively, because physicians release stress on the golf course, or positively owing to decreased availability and time spent away from developing clinical skill)? Do costs of care increase and patient outcomes worsen in the days after a physician has had a bad round of golf? Given research that suggests male physicians spend almost two hours less than female physicians each day on household responsibilities, even among dual physician couples who have similar reported work, ${ }^{17}$ does the substantially greater time spent by male physicians on the golf course explain some of this discrepancy?

\section{Limitations of this study}

Our study has limitations. First, not all physicians who play golf report personal statistics to the Golf Handicap and Information Network database that we used in this study. This database is, however, widely used by amateur golfers who regularly play golf and we found that $5.5 \%$ of male physicians report golf statistics to this database. Still, it is likely that more physicians play golf than estimated by our study. We also have no reason to believe that physicians from different specialties would systematically differ in reporting to this database, which suggests our relative rankings of participation in golf between specialties should be accurate. Second, our analysis involved linkage of two databases according to physician name and state of residence. Incorrect linkages could have occurred-though again, these should not systematically vary across specialties. Third, golfers might also not accurately report their performance, which could bias specialty comparisons if physicians in certain specialties are more likely to overstate golf performance. Fourth, our analysis focused on US physicians, whereas golf is reported to be popular among physicians in the United Kingdom, 
Australia, and likely other countries, though evidence is limited. ${ }^{34}$

\section{Conclusions}

Golfing is common among US physicians, particularly among male physicians and surgical subspecialties. The association between golfing and patient outcomes, costs of care, and physician wellbeing remain unknown.

Contributors: All authors contributed to the design and conduct of the study, data collection and management, analysis and interpretation of the data; and preparation, review, or approval of the manuscript. $A B$ J supervised the study and is the guarantor. The corresponding author attests that all listed authors meet authorship criteria and that no others meeting the criteria have been omitted.

Funding: Support was provided by the Office of the Director, National Institutes of Health (AB), NIH early independence award, grant 1DP50D017897). The research was independent of any involvement from the sponsors of the study. Study sponsors were not involved in the study design, data interpretation, writing, or decision to submit the article for publication.

Competing interests: All authors have completed the ICMJE uniform disclosure form at www.icmje.org/coi disclosure.pdf and declare: support provided by grants from the Office of the Director, National Institutes of Health (AB), NIH early independence award, grant 1DP5OD017897); no financial relationships with any organizations that might have an interest in the submitted work in the previous three years; and no other relationships or activities that could appear to have influenced the submitted work.

Ethical approval: Not required.

Data sharing: No additional data available.

Transparency: The lead author (the manuscript's guarantor) affirms that the manuscript is an honest, accurate, and transparent account of the study being reported; that no important aspects of the study have been omitted; and that any discrepancies from the study as planned (and, if relevant, registered) have been explained.
1 Rotenstein LS, Torre M, Ramos MA, et al. Prevalence of burnout among physicians: A systematic review. JAMA 2018;320:1131-50. doi:10.1001/jama.2018.12777

2 Furlong L. Top Golfer Doctors in America. Golf Digest, 2018.

3 Odone C. Doctors should get off the golf course and into the wards. The Telegraph, 2018.

4 Australian Medical Society (NSW). Golf Society.

5 Murray AD, Archibald D, Murray IR, et al. 2018 International Consensus Statement on Golf and Health to guide action by people, policymakers and the golf industry. Br J Sports Med 2018;52:142614361. doi:10.1136/bjsports-2018-099509

6 Murase Y, Kamei S, Hoshikawa T. Heart rate and metabolic responses to participation in golf. J Sports Med Phys Fitness 1989;29:269-72.

7 Tsang WW, Hui-Chan CW. Effects of exercise on joint sense and balance in elderly men: Tai Chi versus golf Med Sci Sports Exerc 2004;36:658-67. doi:10.1249/01. MSS.0000122077.87090.2E

8 Jastifer J, Roberts S. Patients' awareness of and attitudes toward gifts from pharmaceutical companies to physicians. Int I Health Serv 2009;39:405-14. doi:10.2190/HS.39.2.j

9 Golf Handicap and Information Network. Handicap Lookup.

10 United States Golf Association, USGA Handicap System Manual.

11 Tsugawa Y, Newhouse JP, Zaslavsky AM, Blumenthal DM, Jena AB. Physician age and outcomes in elderly patients in hospital in the US: observational study. BMJ 2017;357:j1797. doi:10.1136/bmj. j1797

12 Tsugawa Y, Jena AB, Figueroa JF, Orav EJ, Blumenthal DM, Jha AK. Comparison of Hospital Mortality and Readmission Rates for Medicare Patients Treated by Male vs Female Physicians. JAMA Intern Med 2017;177:206-13. doi:10.1001/jamainternmed.2016.7875

13 Jena AB, Olenski AR, Blumenthal DM. Sex Differences in Physician Salary in US Public Medical Schools. IAMA Intern Med 2016;176:1294-304. doi:10.1001/ jamainternmed.2016.3284

14 Jena AB, Khullar D, Ho O, Olenski AR, Blumenthal DM. Sex Differences in Academic Rank in US Medical Schools in 2014 JAMA 2015;314:1149-58. doi:10.1001/jama.2015.10680

15 Stachura M. A closer look at handicap data shows just how much golfers have improved in recent years. Golf Digest, 2018.

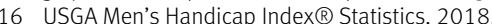

17 Ly DP, Jena AB. Sex Differences in Time Spent on Household Activities and Care of Children Among US Physicians, 2003-2016. Mayo Clin Proc 2018;93:1484-7. doi:10.1016/j.mayocp.2018.02.018t 